\title{
Article \\ Proinflammatory Responses of 1-Nitropyrene against RAW264.7 Macrophages through Akt Phosphorylation and NF-kB Pathways
}

\author{
Ping-Kun Tsai ${ }^{1,2}$, Shih-Pin Chen ${ }^{3,4}$, Rosa Huang-Liu ${ }^{5}$, Chun-Jung Chen ${ }^{6}$, Wen-Ying Chen ${ }^{7}$ D, Yan-Yan Ng ${ }^{8,+}$ \\ and Yu-Hsiang Kuan $9,10, *,+(\mathbb{D}$
}

1 Department of Internal Medicine, Zuoying Branch of Kaohsiung Armed Forces General Hospital, Kaohsiung 81342, Taiwan; pingkun@hotmail.com

2 Department of Emergency Medicine, Tri-Service General Hospital, National Defense Medical Center, Taipei 11490, Taiwan

3 Department of Internal Medicine, School of Medicine, Chung Shan Medical University, Taichung 40201, Taiwan; cshy752@csh.org.tw

4 Department of Internal Medicine, Chung Shan Medical University Hospital, Taichung 40201, Taiwan

5 School of Nutrition, Chung Shan Medical University, Taichung 40201, Taiwan; rhl@csmu.edu.tw

6 Department of Education and Research, Taichung Veterans General Hospital, Taichung 40705, Taiwan; cjchen@vghtc.gov.tw

7 Department of Veterinary Medicine, National Chung Hsing University, Taichung 40227, Taiwan; wychen@dragon.nchu.edu.tw

8 Department of Pediatric, Chung Kang Branch, Cheng Ching Hospital, Taichung 40764, Taiwan; angeleng77@gmail.com

check for updates

Citation: Tsai, P.-K.; Chen, S.-P.; Huang-Liu, R.; Chen, C.-J.; Chen, W.-Y.; Ng, Y.-Y.; Kuan, Y.-H. Proinflammatory Responses of 1-Nitropyrene against RAW264.7 Macrophages through Akt Phosphorylation and NF- $\kappa B$ Pathways. Toxics 2021, 9, 276 https://doi.org/10.3390/ toxics 9110276

Academic Editor: Alison K. Bauer

Received: 24 August 2021

Accepted: 14 October 2021

Published: 21 October 2021

Publisher's Note: MDPI stays neutral with regard to jurisdictional claims in published maps and institutional affiliations.

Copyright: (c) 2021 by the authors. Licensee MDPI, Basel, Switzerland. This article is an open access article distributed under the terms and conditions of the Creative Commons Attribution (CC BY) license (https:/ / creativecommons.org/licenses/by/ $4.0 /)$.
9 Department of Pharmacy, Chung Shan Medical University Hospital, Taichung 40201, Taiwan

10 Department of Pharmacology, School of Medicine, Chung Shan Medical University, Taichung 40201, Taiwan

* Correspondence: kuanyh@csmu.edu.tw; Tel.: +886-4-2473-0022 (ext. 11662); Fax: +886-4-2473-9030

$+\quad$ These authors contributed equally to this work.

\begin{abstract}
Air pollution is a major environmental and public health problem worldwide. A nitropolycyclic aromatic hydrocarbon and the most abundant air pollutant in diesel engine exhaust, 1-nitropyrene (1-NP), is caused by the incomplete combustion of carbonaceous organic substances. Macrophages are effector cells of the innate immune cells that provide resistance in the peripheral tissue. The overactivation of macrophages results in inflammation. The generation of proinflammatory cytokines, such as interleukin (IL)-1 $\beta$, IL-6, and tumour necrosis factor alpha, is induced by $1-\mathrm{NP}$ in a concentration-dependent manner in macrophages. In this study, the production of proinflammatory mediators, such as nitrogen oxide and prostaglandin E2, was induced by 1-NP in a concentration-dependent manner through the expression of iNOS and COX2. The generation of proinflammatory cytokines, iNOS, and COX2 was induced by 1-NP through nuclear factor (NF)-kB p65 phosphorylation and the degradation of its upstream factor, IKB. Finally, Akt phosphorylation was induced by 1-NP in a concentration-dependent manner. These findings suggest that 1-NP exhibits a proinflammatory response through the NF- $\mathrm{kB}$ pathway activation due to Akt phosphorylation.
\end{abstract}

Keywords: 1-nitropyrene; proinflammatory cytokines; PGE2; NF-kB pathway; Akt

\section{Introduction}

Air pollution is caused by a mixture of pollutants floating in the atmosphere. These pollutants are generated from natural events, such as fires, storms, volcanic eruptions, and the release of pollen. Furthermore, a major source of air pollutants is human activity, such as fossil fuel combustion, agricultural activity, manufacturing (particularly in the form of factory exhausts), and mining [1-3]. Exposure to air pollutants is associated with many diseases, including cardiovascular diseases, neurodegenerative diseases, diabetes, and glaucoma $[1,2,4,5]$. Known as a nitro-polycyclic aromatic hydrocarbon and the most abundant nitroarene in diesel engine exhaust, 1-nitropyrene (1-NP) results from the incomplete combustion of carbonaceous organic substances [6,7]. Genotoxicity and apoptosis are 
induced by 1-NP in macrophages, liver and lung epithelial cells, and hepatoma cells [8-12]. Chronic inflammation in pulmonary fibrosis is induced by 1-NP through endoplasmic reticulum stress in mice [13]. Cytokines and chemokines are induced by 1-NP in the alveolar epithelial cell line A549 and the human bronchial epithelial cell line BEAS-2B [14,15].

Inflammation is a crucial defence mechanism against invasive microorganisms and inhaled air pollution, including diesel engine exhaust and particulate matter. The elimination of microorganisms and air pollutants due to proinflammatory mediators is accompanied by inflammation in peripheral tissues [16-18]. Macrophages are effector cells of the innate immune cells that provide resistance in the peripheral tissue [16]. Therefore, macrophage activation is involved in the action of proinflammatory mediators, including cytokines, nitrogen oxide (NO), and prostaglandin E2 (PGE2) $[19,20]$. The activation of the proinflammatory transcript factor nuclear factor (NF)- $\mathrm{kB}$ is induced by environmental pollutants in macrophages through the phosphoinositide 3-kinase (PI3K) and Akt signalling pathways $[21,22]$. However, the effects of 1-NP-induced inflammation in macrophages remain unclear. Thus, this study examined the proinflammatory responses and relative mechanisms of macrophage RAW264.7 cells treated with 1-NP.

\section{Materials and Methods}

\subsection{Materials}

Primary antibodies for cyclooxygenase-2 (COX-2), inducible nitric oxide synthase (iNOS), phosphoryl (P)-Akt, Akt, P-p38 mitogen-activated protein kinase (MAPK), p38 MAPK, P-p65, p65, I $\kappa$ B, and $\beta$-actin were obtained from Santa Cruz Biotechnology (Santa Cruz, CA, USA). All secondary antibodies used for Western blot assays were purchased from Jackson ImmunoResearch Laboratories (Baltimore, MD, USA). ELISA kits for interleukin (IL)-1 $\beta$, IL-6, tumour necrosis factor (TNF) $\alpha$, and prostaglandin (PG) E2 were purchased from Cayman Chemicals (Ann Arbor, MI, USA). All agents for cell culture were purchased from HyClone Laboratories (Logan, UT, USA). A Griess reaction assay kit, 1-NP, phosphate-buffered saline (PBS), dimethyl sulphoxide (DMSO), and other agents were obtained from Sigma-Aldrich (St. Louis, MO, USA). In this work, 1-NP was dissolved in DMSO and the final concentration of DMSO was found to be less than $0.05 \%$ in each test sample.

\subsection{Cell Culture and Treatment}

RAW264.7 murine macrophage-like cells purchased from the Bioresource Collection and Research Centre (BCRC, Hsinchu, Taiwan) were cultured in DMEM supplemented with $50 \mathrm{IU} / \mathrm{mL}$ penicillin and $100 \mu \mathrm{g} / \mathrm{mL}$ streptomycin at $37^{\circ} \mathrm{C}$ in an atmosphere of $5 \%$ $\mathrm{CO}_{2}$ and $95 \%$ air. RAW264.7 cells were plated at a density of $5 \times 10^{5}$ cells $/ \mathrm{mL}$ for $12 \mathrm{~h}$, then the medium was replaced with a serum-free DMEM medium [11,12]. After cell incubation with 1-NP at the concentrations of $0,3,10,30$, and $50 \mu \mathrm{M}$ for $30 \mathrm{~min}$ or $12 \mathrm{~h}$, supernatants were collected for an enzyme-linked immunosorbent assay (ELISA) and Griess reaction assays; the cells were harvested for a protein expression assay.

\subsection{ELISA Assay}

The levels of interleukin (IL)-1 $\beta$, IL-6, tumour necrosis factor alpha (TNF $\alpha$ ), and PGE2 were measured using an ELISA assay kit according to the manufacturer's instructions and the assay procedures of a previous study $[23,24]$. After cells were incubated with 1-NP at the indicated concentrations for $12 \mathrm{~h}$, the supernatants were harvested and loaded into plates coated with anticytokine antibodies for $16 \mathrm{~h}$ at $4{ }^{\circ} \mathrm{C}$. After being washed, biotinconjugated anticytokine antibodies were placed onto a plate for $2 \mathrm{~h}$ at room temperature. After washing, streptavidin HRP solution and TMB substrate solution were loaded onto the plate. Sulfuric acid was used to stop the reaction and the absorbance was measured at $450 \mathrm{~nm}$ using a microplate reader (Synergy HT Multi-Mode Microplate Reader, Biotek, Winooski, VT, USA). 


\subsection{Griess Reaction Assay}

After the cells were incubated with 1-NP at the indicated concentrations for $12 \mathrm{~h}$, the level of NO production in the medium was detected with the Griess reaction. The same volumes of $1 \%$ sulphanilamide dissolved in $5 \%$ phosphoric acid and $0.1 \% \mathrm{~N}$-(1-naphthyl) ethylenediamine dihydrochloride dissolved in water were added to the medium. The absorbance at $540 \mathrm{~nm}$ was determined using a microplate reader. The nitrite concentration in the samples was determined with reference to the dilution of sodium nitrite as a standard [20].

\subsection{Western Blotting Assay}

After cells were incubated with 1-NP at the indicated concentrations for $12 \mathrm{~h}$, they were washed with ice-cold PBS and solubilised in RIPA lysis buffer [23,24]. Equal amounts of the protein were denatured in SDS, electrophoresed on SDS-PAGE, and transferred to polyvinylidene difluoride membranes. The membranes were probed with primary antibodies. After being washed, the membranes were re-probed with HRP-conjugated secondary antibodies. All membranes were developed and quantified with enhanced chemiluminescence labelling solution using an Infinity CX5 detection system (Vilber Lourmat, France).

\subsection{Statistical Analysis}

All the experiments were repeated at least thrice. Values were expressed in terms of the mean \pm standard deviation (S.D.). The significance of the difference from the respective controls for each experimental test condition was assessed using a one-way ANOVA, followed by Bonferroni's multiple comparisons post hoc test. Data were analysed using the SPSS software. A $p$ value $<0.05$ was considered significant.

\section{Results}

3.1. Effects of 1-NP on Proinflammatory Cytokine Generation in RAW264.7 Macrophages

ELISA assays were used to quantify proinflammatory cytokines, such as IL-1 $\beta$, IL-6, and $\mathrm{TNF} \alpha$, generated in the medium of RAW264.7 macrophages. As illustrated in Figure 1, 1-NP-treated cells produced significantly more proinflammatory cytokines than the control cells $(p<0.05)$. Proinflammatory cytokine inhibition presented in a concentrationdependent manner and a significant increase was seen starting at $10 \mu \mathrm{M}(p<0.05)$.

\subsection{Effects of 1-NP on NO Generation and iNOS Expression in RAW264.7 Macrophages}

The NO generation induced by 1-NP was measured using a Griess reaction assay on RAW264.7 macrophages. After RAW264.7 macrophages had been incubated with 1-NP for $12 \mathrm{~h}, \mathrm{PGE} 2$ and NO were generated in a concentration-dependent manner and a significant increase was observed at $10 \mu \mathrm{M}(p<0.05$, Figure 2$)$. iNOS is the upstream factor of NO generation. The expression of iNOS was induced by 1-NP in a concentration-dependent manner, and a significant increase was seen starting at $10 \mu \mathrm{M}(p<0.05$, Figure 2$)$.

\subsection{Effects of 1-NP on PGE2 Production, COX2 Expression, and cPLA2 Phosphorylation in RAW264.7 Macrophages}

The PGE2 production induced by 1-NP was measured using an ELISA assay. After RAW264.7 macrophages were incubated with 1-NP for $12 \mathrm{~h}$, PGE2 production was induced by 1-NP in a concentration-dependent manner, and a significant increase was seen starting at $10 \mu \mathrm{M}(p<0.05$, Figure 3$)$. COX2 expression and cPLA2 phosphorylation are upstream factors of PGE2 production. COX2 expression and cPLA2 phosphorylation were induced by 1-NP in a concentration-dependent manner, and a significant increase was seen starting at $10 \mu \mathrm{M}(p<0.05$, Figure 3$)$. 

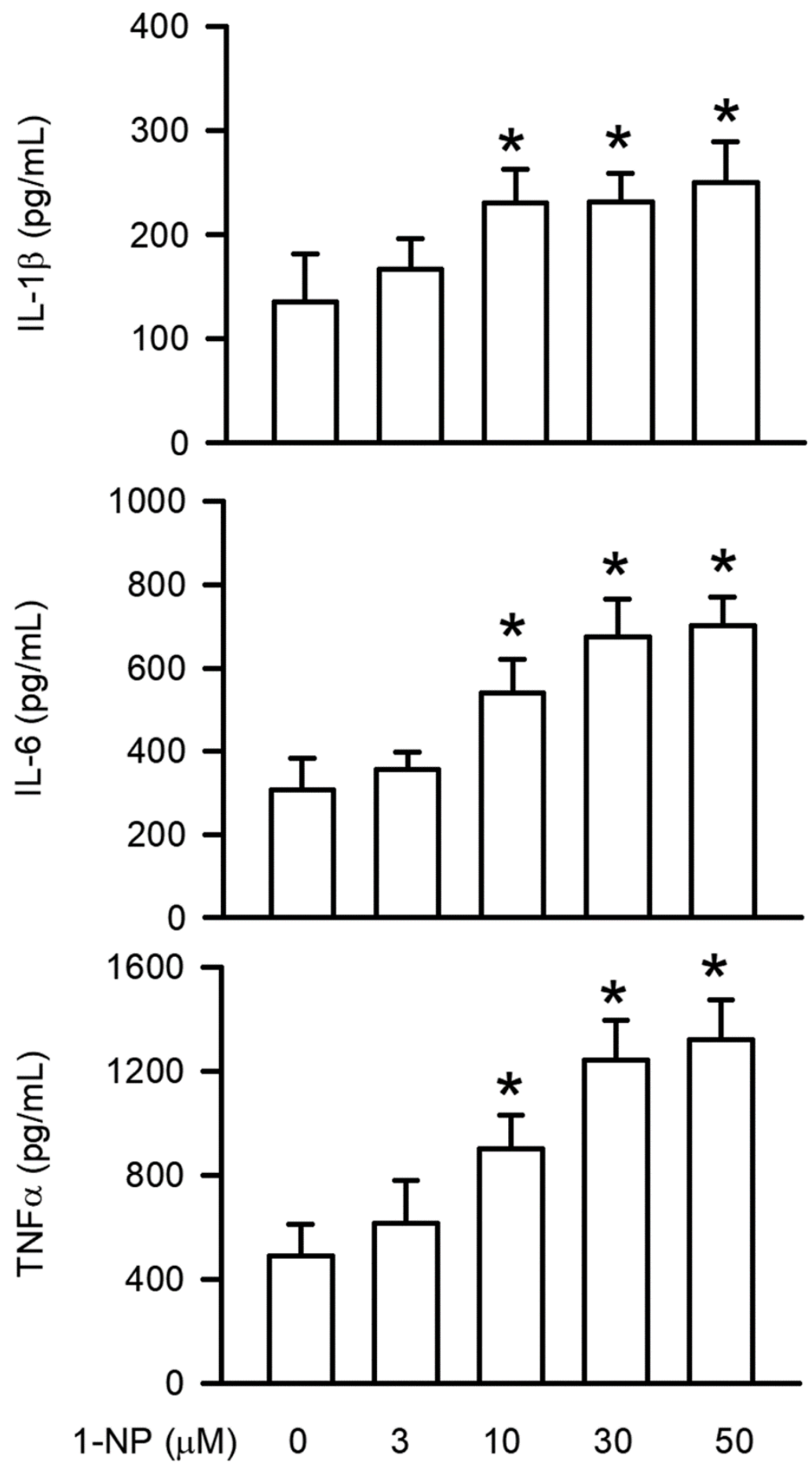

Figure 1. Proinflammatory cytokine generation was induced by 1-NP in RAW264.7 macrophages. Proinflammatory cytokines, including IL- $1 \beta, \mathrm{IL}-6$, and TNF $\alpha$, were determined by the ELISA assay. Results are expressed as means $\pm \mathrm{SD}(n=4) .{ }^{*} p<0.05$ is considered significant, compared with the control group, which indicated treatment with $1-\mathrm{NP}$ at $0 \mu \mathrm{M}$. 


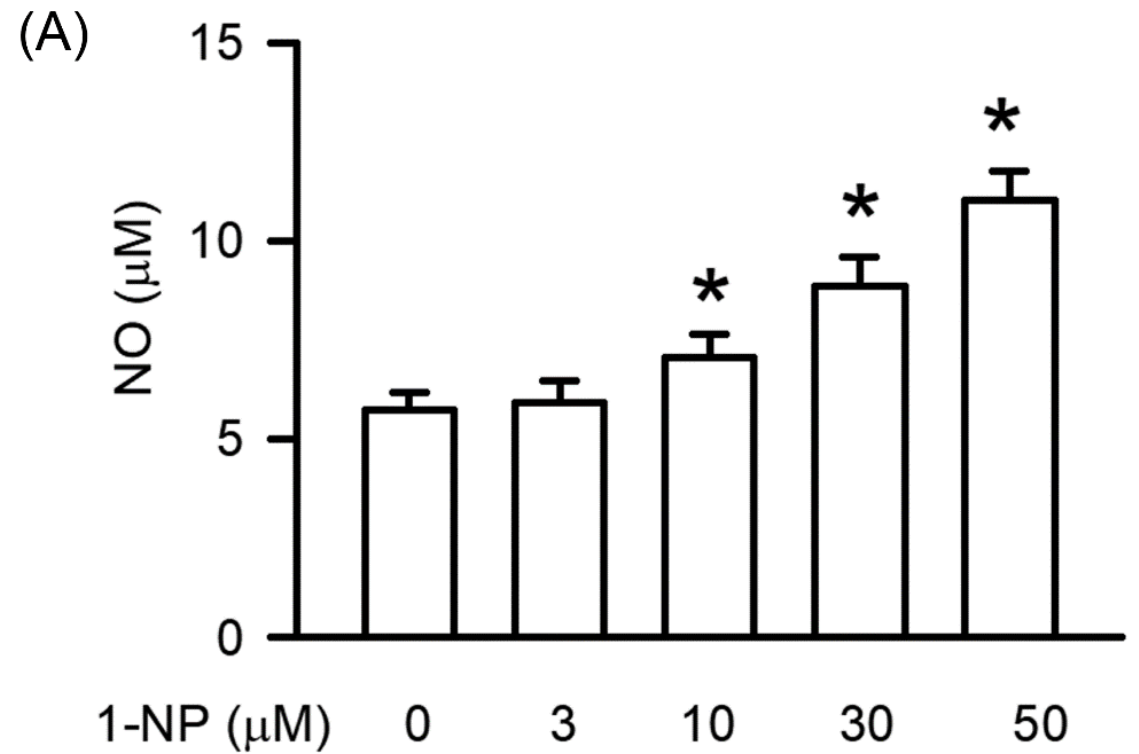

(B)
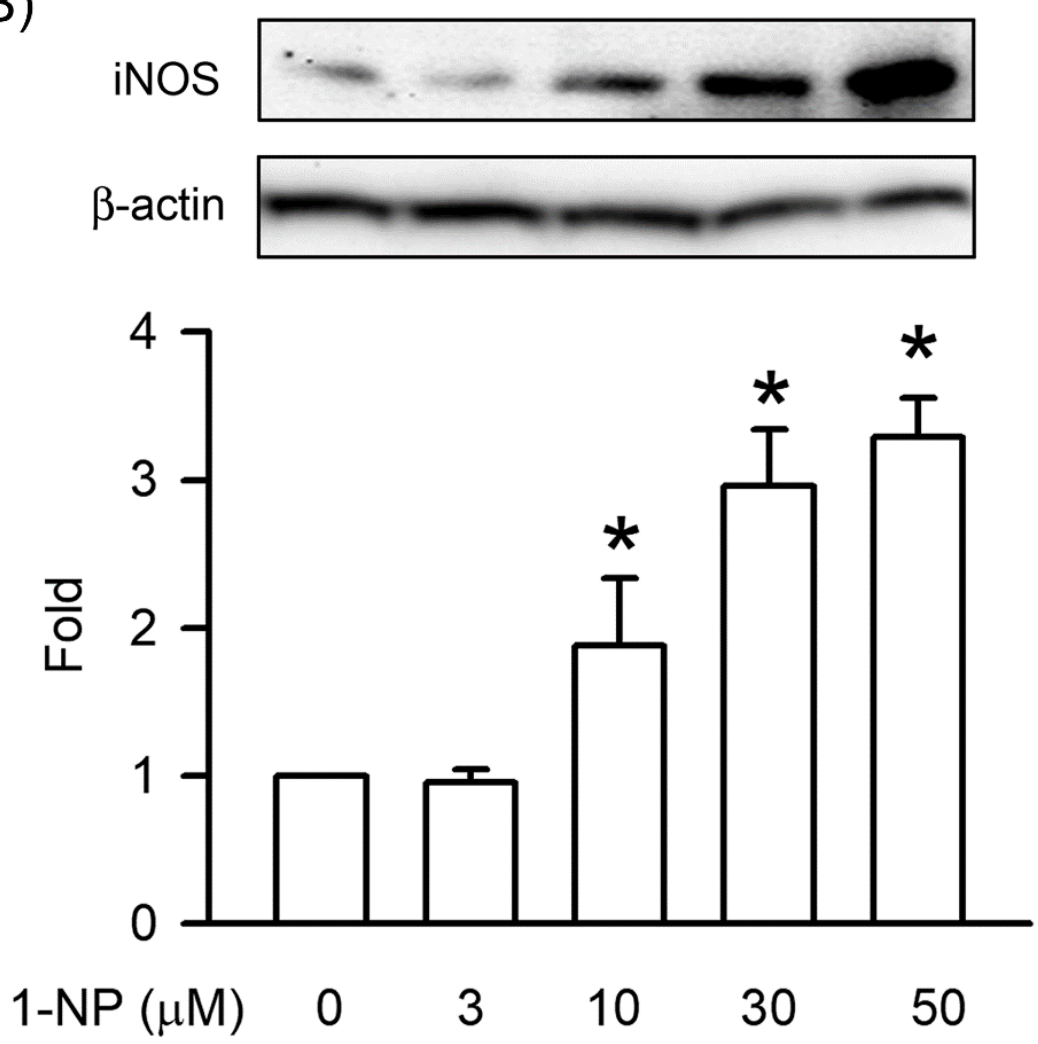

Figure 2. NO generation and iNOS expression were induced by 1-NP in RAW264.7 macrophages. The level of NO generation (A) and iNOS expression (B) was measured by a Griess reaction assay and Western blotting assay, respectively. Results are expressed as means $\pm \operatorname{SD}(n=3) .{ }^{*} p<0.05$ is considered significant, compared with the control group, which indicated treatment with 1-NP at $0 \mu \mathrm{M}$. 
(A)

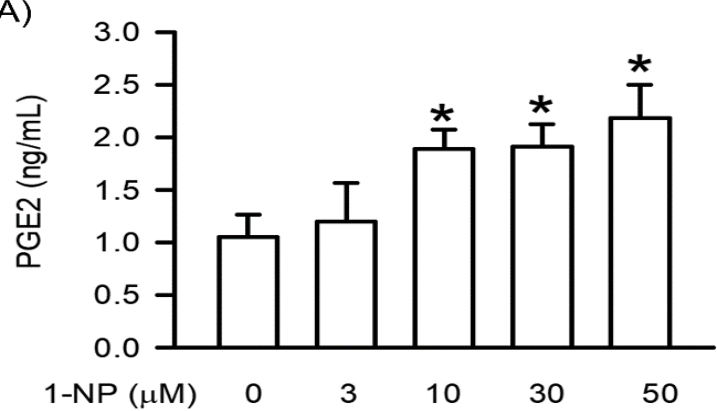

(B)
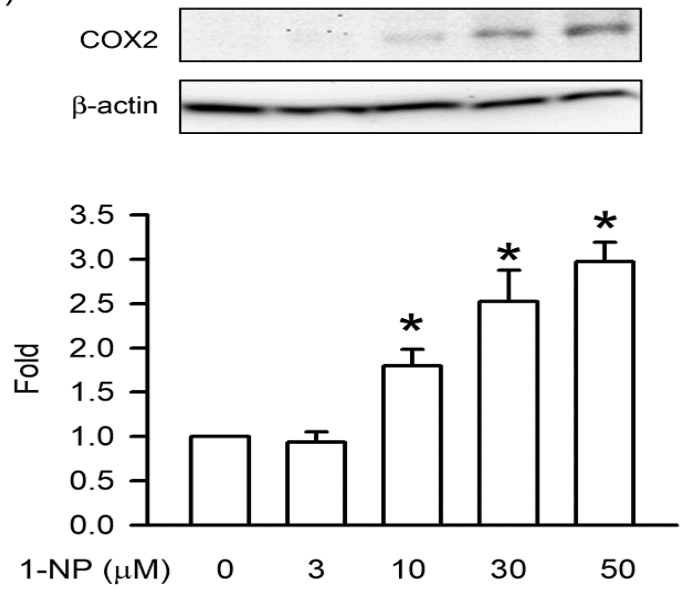

(C)

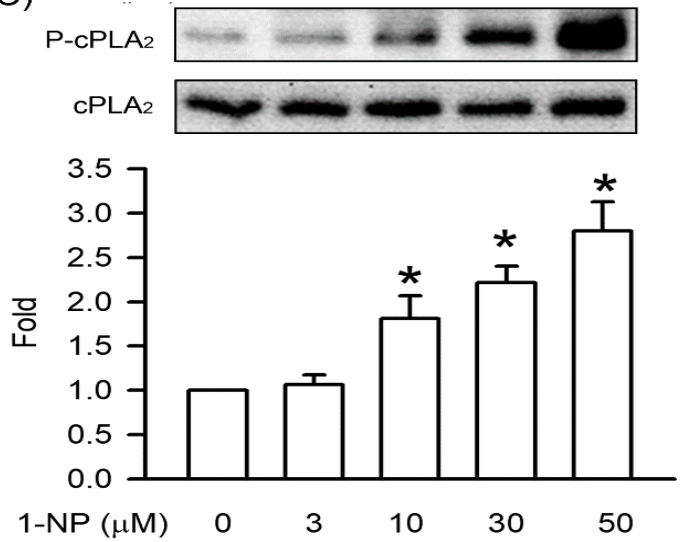

Figure 3. PGE2 production, COX2 expression, and cPLA2 phosphorylation were induced by 1-NP in RAW264.7 macrophages. (A) The level of PGE2 generation was measured by ELISA assay. The level of COX2 expression (B) and cPLA2 phosphorylation (C) was measured by Western blotting assay. Results are expressed as means $\pm \operatorname{SD}(n=3) .{ }^{*} p<0.05$ is considered significant, compared with the control group, which indicated treatment with $1-\mathrm{NP}$ at $0 \mu \mathrm{M}$.

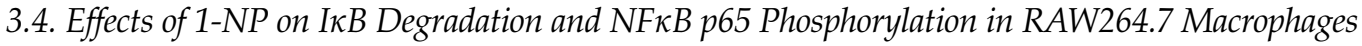

The activation of the proinflammatory transcript factor NF- $\mathrm{B}$ p 65 plays an essential role in the generation of proinflammatory cytokines and mediators. I $\mathrm{B}$ degradation and

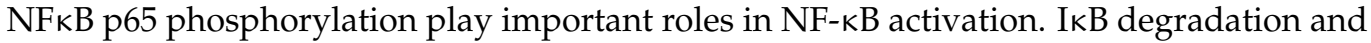
NFKB p65 phosphorylation were significantly higher relative to such levels in control cells after treatment with 1-NP for $12 \mathrm{~h}$ ( $p<0.05$, Figure 4$)$. The phosphorylation of p65 presented in a concentration-dependent manner, and a significant increase was seen starting at $10 \mu \mathrm{M}$ $(p<0.05$, Figure 4$)$. 
(A)

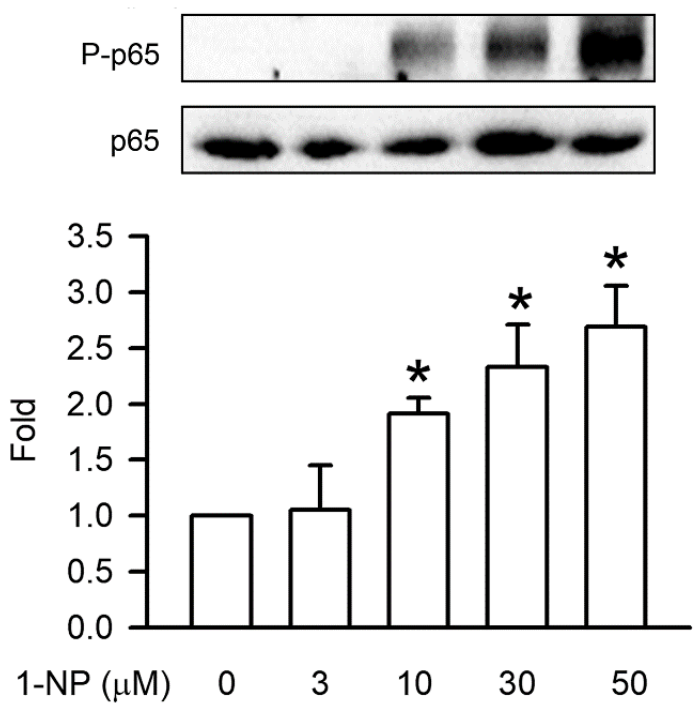

(B)
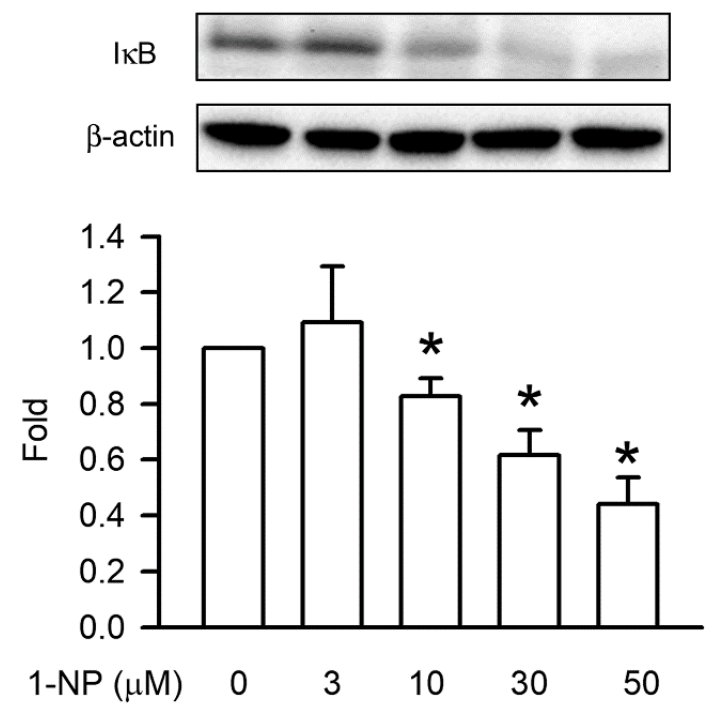

Figure 4. NFkB p65 phosphorylation and IkB degradation were induced by 1-NP in RAW264.7 macrophages. The level of NFkB p65 phosphorylation (A) and IкB degradation (B) was measured by a Western blotting assay. Results are expressed as means $\pm \mathrm{SD}(n=3)$. ${ }^{*} p<0.05$ is considered significant, compared with the control group, which indicated treatment with $1-\mathrm{NP}$ at $0 \mu \mathrm{M}$.

\subsection{Effects of 1-NP on Akt Phosphorylation in RAW264.7 Macrophages}

Akt phosphorylation is a crucial upstream factor in NF- $\mathrm{kB}$ activation and involves IкB degradation. Akt phosphorylation was analysed in cells treated with 1-NP for $30 \mathrm{~min}$. The phosphorylation of Akt in RAW264.7 cells stimulated with 1-NP increased markedly in a concentration-dependent manner, and a significant increase was seen starting at $10 \mu \mathrm{M}$ $(p<0.05$, Figure 5).
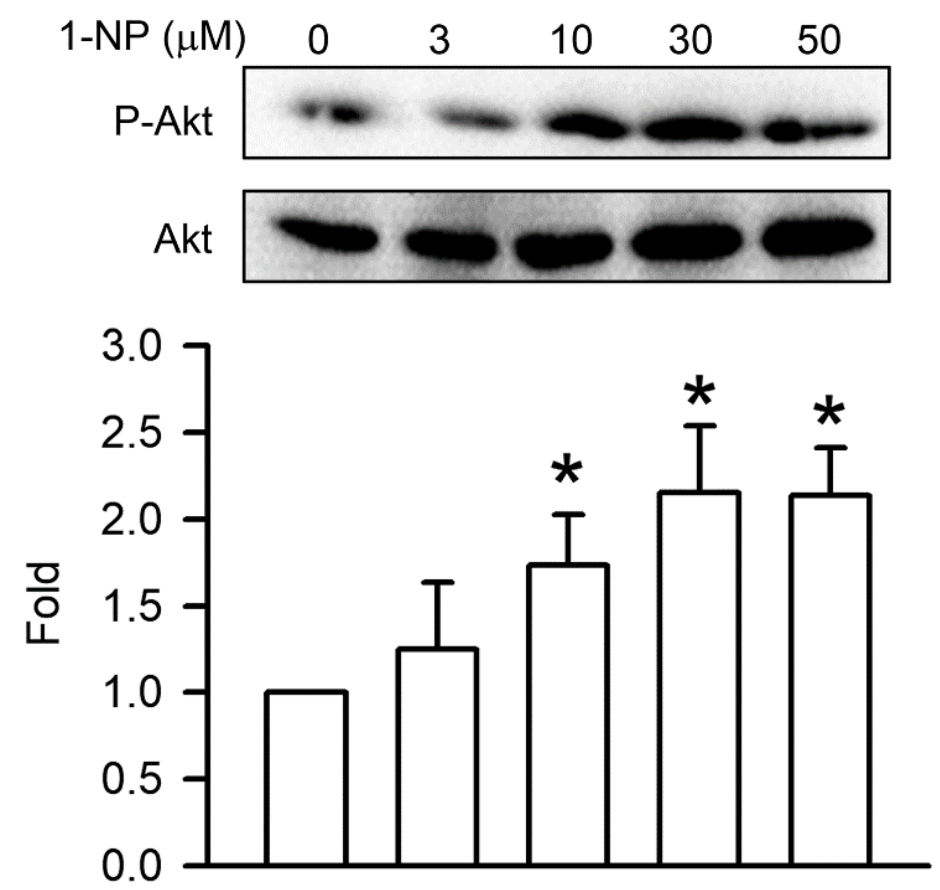

Figure 5. Akt phosphorylation was induced by 1-NP in RAW264.7 macrophages. The level of Akt phosphorylation was measured by a Western blotting assay. Results are expressed as means \pm SD $(n=3) .{ }^{*} p<0.05$ is considered significant, compared with the control group, which indicated treatment with $1-\mathrm{NP}$ at $0 \mu \mathrm{M}$. 


\section{Discussion}

The solubility and concentration of 1-NP are very low in the gas phase [25]. However, 1-NP is adsorbed as an air pollutant from diesel engine exhaust fumes and particulate matter. Previous studies have reported that concentrations of 1-NP from 0.5 to $275 \mu \mathrm{M}$ in exhaust emissions from gasoline-powered engines, light-duty diesel-powered engines, and heavy-duty diesel-powered engines [26]. Therefore, we employed 1-NP at a level of 3 to $50 \mu \mathrm{M}$ for this study. In our previous studies, we found that cytotoxicity was induced by 1-NP in a time- and concentration-dependent manner. After 1-NP was incubated with RAW264.7 cells for $12 \mathrm{~h}$, the cytotoxicity was approximately 10,20 , and $35 \%$ at concentrations of 10,30 , and $50 \mu \mathrm{M}$, respectively. After 1-NP was incubated with RAW264.7 cells for $24 \mathrm{~h}$ and $48 \mathrm{~h}$, more serious levels of cytotoxicity were generated [11,12]. Based on these findings, we suggest that cytotoxicity induced by 1-NP cannot be recovered. The longer it takes to treat cells with 1-NP, the greater are the harmful effects on the cells, and the more likely it is that the caused damage leads to cytotoxicity.

In previous studies, we found that cytotoxicity was induced by 1-NP in a time- and concentration-dependent manner. With the same duration of 1-NP treatment of $12 \mathrm{~h}$, the level of cytotoxicity was approximately 10, 20, and 35\% at concentrations of 10, 30, and $50 \mathrm{mM}$, respectively. After 1-NP was incubated with RAW264.7 cells for 24 and $48 \mathrm{~h}$, more serious levels of cytotoxicity were generated. These findings suggest that the cytotoxicity induced by 1-NP cannot be recovered. In addition, the cytotoxicity and genotoxicity induced by 1-NP may occur via intracellular accumulation and metabolism [11,12]. Based on these findings, we hypothesise that the proinflammatory response is higher than the toxic effects after 1-NP is incubated with RAW264.7 cells for $12 \mathrm{~h}$.

Macrophages play a crucial role in the innate immunity system in phagocytosis, digestion, and the elimination of invasive pathogens, microorganisms, and air pollutants through the generation of proinflammatory cytokines such as IL-1 $\beta$, IL-6, and TNF $\alpha$ [27-29]. In addition to the linkage between innate and adaptive immunity, IL-1 $\beta$, IL6, and TNF $\alpha$ were found to induce acute and strong inflammatory responses, including leukocyte recruitment and proinflammatory mediator generation. These inflammatory responses cause excessive damage to peripheral tissues and then result in pathological diseases, such as atherosclerosis, adult respiratory distress syndrome, and tumours [30-32]. The levels of IL-1 $\beta$, IL6, and $\mathrm{TNF} \alpha$ in mRNA are upregulated by 1-NP in mouse lungs [33]. The generation of IL-1 $\beta$, IL6, and TNF $\alpha$ is induced by 1-NP in the human alveolar basal epithelial cell line, specifically in A549 cells, and the human bronchial epithelial cell line, specifically in BEAS-2B cells [15,29]. The findings of this study revealed that the production of IL-1 $\beta$, IL6, and TNF $\alpha$ is induced by 1 -NP in a concentration-dependent manner in RAW264.7 cells. These results suggest that proinflammatory cytokines are induced by 1-NP in macrophages.

In inflammatory pathogenesis, the excessive production of NO and PGE2 is an important contributor. After macrophages were treated with proinflammatory stimuli, NO and PGE2 were generated from iNOS and COX-2, respectively. In addition, CPLA2 phosphorylation was involved in COX-2-dependent PGE2 generation in macrophages $[19,34]$. This result is the first to demonstrate that 1-NP-induced NO generation occurs through iNOS upregulation and PGE2 production by the upregulation of COX-2 through cPLA2 phosphorylation. The present results reveal that inflammatory responses are induced by 1-NP in macrophages through the generation of proinflammatory mediators, such as NO and PGE2, and proinflammatory cytokines, such as IL-1 $\beta$, IL6, and TNF $\alpha$.

$\mathrm{NF}-\mathrm{kB}$ acts as the major nuclear transcription factor promoter and stimulates the generation of proinflammatory mediators. NF- $\mathrm{kB}$ p65, also called RelA, is the most abundant functional subunit of NF- $\kappa$ B. I $\kappa B$ is a critical upstream factor of NF- $\kappa B$ activation. In the normal resting state of macrophages, I $\kappa B$ binds with NF- $\kappa B$ to create complex resistance in the cytosol $[24,35]$. After macrophages are exposed to pollutants and stimulants, NF- $k B$ p65 is liberated from the IкB-NF- $\mathrm{kB}$ complex, translocated from the cytosol to nuclear, and bound to DNA to enhance the expression of proinflammatory mediators. At the same time, IKB is degraded by the proteasome in the cytosol. As has been shown previously, the 
phosphorylation of NF-kB p65 was increased by 1-NP in A549 cells and mouse lungs [33]. In this study, we further found the phosphorylation of p65 through the degradation of I KB in 1-NP-treated RAW264.7 macrophages. These results suggest that the generation of proinflammatory mediators is stimulated by 1-NP via the activation of the NF- $\mathrm{KB}$ pathway, including NF- $\mathrm{KB}$ p 65 phosphorylation and IKB degradation.

In the pathogenesis of inflammation, the PI3K/Akt pathway plays a key role in mammal cells and animals. Akt, also named protein kinase B, is an important downstream effector of PI3K [36]. The activation of the NF- $\kappa B$ pathway is enhanced by Akt phosphorylation in the macrophages. After the treatment of mouse lungs and A549 cells with 1-NP, the phosphorylation of Akt was upregulated [10,33]. Here, the phosphorylation of Akt was induced by 1-NP in macrophages. Moreover, the concentration trend of Akt phosphorylation is similar to that of NF- $\mathrm{kB}$ pathway activation, including NF- $\mathrm{kB}$ p65 phosphorylation and IKB degradation, in 1-NP treated with RAW264.7 macrophages. These results indicate that NF-kB pathway activation is induced by 1-NP through Akt phosphorylation.

Our results demonstrate that the generation of proinflammatory mediators, such as NO and PGE2, is induced by 1-NP through the expression of iNOS and COX2. The expression of proinflammatory cytokines, including IL-1 $\beta$, IL-6, and TNF $\alpha$, was also induced by 1-NP. The expression of proinflammatory mediators and cytokines was induced by 1-NP through the activation of the NF- $\mathrm{kB}$ pathway and its upstream factor, Akt phosphorylation. In conclusion, inflammatory responses were induced by 1-NP through the activation of the NF- $\mathrm{kB}$ pathway via Akt phosphorylation.

Author Contributions: Conceptualisation, P.-K.T., Y.-Y.N. and Y.-H.K.; data curation, P.-K.T., S.-P.C., R.H.-L. and W.-Y.C.; formal analysis, R.H.-L., C.-J.C. and Y.-Y.N.; funding acquisition, P.-K.T., Y.-Y.N. and Y.-H.K.; investigation, P.-K.T., S.-P.C. and W.-Y.C.; methodology, S.-P.C., R.H.-L., C.-J.C., W.-Y.C. and Y.-H.K.; software, R.H.-L.; supervision, Y.-H.K.; validation, S.-P.C., W.-Y.C. and Y.-H.K.; writingoriginal draft preparation, P.-K.T., S.-P.C. and C.-J.C.; writing-review and editing, Y.-Y.N. and Y.-H.K. All authors have read and agreed to the published version of the manuscript.

Funding: This study was supported by research grants from the Ministry of Science and Technology of Taiwan (MOST 109-2320-B-040-MY3). We also thank the National Chung Hsing University and Chung Shan Medical University (NCHU-CSMU-10810 and NCHU-CSMU-11005) and the Zuoying Branch of Kaohsiung Armed Forces General Hospital under Grant No. ZBH108-07.

Institutional Review Board Statement: Not applicable.

Informed Consent Statement: Not applicable.

Data Availability Statement: The data presented in this study are available on request from the corresponding author.

Conflicts of Interest: The authors declare no conflict of interest.

\section{References}

1. Abera, A.; Friberg, J.; Isaxon, C.; Jerrett, M.; Malmqvist, E.; Sjöström, C.; Taj, T.; Vargas, A.M. Air Quality in Africa: Public Health Implications. Annu. Rev. Public Health 2021, 42, 193-210. [CrossRef]

2. Ain, N.U.; Qamar, S.U.R. Particulate Matter-Induced Cardiovascular Dysfunction: A Mechanistic Insight. Cardiovasc. Toxicol. 2021, 21, 505-516. [CrossRef] [PubMed]

3. Sridharan, S.; Kumar, M.; Singh, L.; Bolan, N.S.; Saha, M. Microplastics as an emerging source of particulate air pollution: A critical review. J. Hazard. Mater. 2021, 418, 126245. [CrossRef] [PubMed]

4. Li, R.L.; Ho, Y.C.; Luo, C.W.; Lee, S.S.; Kuan, Y.H. Influence of PM(2.5) Exposure Level on the Association between Alzheimer's Disease and Allergic Rhinitis: A National Population-Based Cohort Study. Int. J. Environ. Res. Public Health 2019, $16,3357$. [CrossRef] [PubMed]

5. Sun, H.Y.; Luo, C.W.; Chiang, Y.W.; Yeh, K.L.; Li, Y.C.; Ho, Y.C.; Lee, S.S.; Chen, W.Y.; Chen, C.J.; Kuan, Y.H. Association Between PM(2.5) Exposure Level and Primary Open-Angle Glaucoma in Taiwanese Adults: A Nested Case-Control Study. Int. J. Environ. Res. Public Health 2021, 18, 1714. [CrossRef] [PubMed]

6. Bamford, H.A.; Bezabeh, D.Z.; Schantz, S.; Wise, S.A.; Baker, J.E. Determination and comparison of nitrated-poly-cyclic aromatic hydrocarbons measured in air and diesel particulate reference materials. Chemosphere 2003, 50, 575-587. [CrossRef] 
7. Gao, Y.; Yang, L.; Chen, J.; Li, Y.; Jiang, P.; Zhang, J.; Yu, J.; Wang, W. Nitro and oxy-PAHs bounded in PM2.5 and PM1.0 under different weather conditions at Mount Tai in Eastern China: Sources, long-distance transport, and cancer risk assessment. Sci. Total Environ. 2018, 622-623, 1400-1407. [CrossRef]

8. Asare, N.; Landvik, N.E.; Lagadic-Gossmann, D.; Rissel, M.; Tekpli, X.; Ask, K.; Låg, M.; Holme, J.A. 1-Nitropyrene (1-NP) induces apoptosis and apparently a non-apoptotic programmed cell death (paraptosis) in Hepa1c1c7 cells. Toxicol. Appl. Pharmacol. 2008, 230, 175-186. [CrossRef]

9. Shang, Y.; Zhou, Q.; Wang, T.; Jiang, Y.; Zhong, Y.; Qian, G.; Zhu, T.; Qiu, X.; An, J. Airborne nitro-PAHs induce Nrf2/ARE defense system against oxidative stress and promote inflammatory process by activating PI3K/Akt pathway in A549 cells. Toxicol. In Vitro 2017, 44, 66-73. [CrossRef]

10. Wu, S.W.; Su, C.H.; Ho, Y.C.; Huang-Liu, R.; Tseng, C.C.; Chiang, Y.W.; Yeh, K.L.; Lee, S.S.; Chen, W.Y.; Chen, C.J.; et al. Genotoxic effects of 1-nitropyrene in macrophages are mediated through a p53-dependent pathway involving cytochrome c release, caspase activation, and PARP-1 cleavage. Ecotoxicol. Environ. Saf. 2021, 213, 112062. [CrossRef]

11. Su, C.H.; Ho, Y.C.; Lee, M.W.; Tseng, C.C.; Lee, S.S.; Hsieh, M.K.; Chen, H.H.; Lee, C.Y.; Wu, S.W.; Kuan, Y.H. 1-Nitropyrene Induced Reactive Oxygen Species-Mediated Apoptosis in Macrophages through AIF Nuclear Translocation and AMPK/Nrf2/HO-1 Pathway Activation. Oxid. Med. Cell. Longev. 2021, 2021, 9314342. [CrossRef] [PubMed]

12. Fu, L.; Zhao, H.; Xiang, Y.; Xiang, H.X.; Hu, B.; Tan, Z.X.; Lu, X.; Gao, L.; Wang, B.; Wang, H.; et al. Reactive oxygen species-evoked endoplasmic reticulum stress mediates 1-nitropyrene-induced epithelial-mesenchymal transition and pulmonary fibrosis. Environ. Pollut. 2021, 283, 117134. [CrossRef] [PubMed]

13. Ovrevik, J.; Låg, M.; Holme, J.A.; Schwarze, P.E.; Refsnes, M. Cytokine and chemokine expression patterns in lung epithelial cells exposed to components characteristic of particulate air pollution. Toxicology 2009, 259, 46-53. [CrossRef] [PubMed]

14. Pei, X.H.; Nakanishi, Y.; Inoue, H.; Takayama, K.; Bai, F.; Hara, N. Polycyclic aromatic hydrocarbons induce IL-8 expression through nuclear factor kappaB activation in A549 cell line. Cytokine 2002, 19, 236-241. [CrossRef]

15. Atri, C.; Guerfali, F.Z.; Laouini, D. Role of Human Macrophage Polarization in Inflammation during Infectious Diseases. Int. J. Mol. Sci. 2018, 19, 1801. [CrossRef]

16. Gallo, M.; Street, M.E.; Guerra, F.; Fanos, V.; Marcialis, M.A. A review of current knowledge on Pollution, Cigarette Smoking and COVID-19 diffusion and their relationship with inflammation. Acta Biomed. 2020, 91, e2020148.

17. Ziegler, K.; Kunert, A.T.; Reinmuth-Selzle, K.; Leifke, A.L.; Widera, D.; Weller, M.G.; Schuppan, D.; Fröhlich-Nowoisky, J.; Lucas, K.; Pöschl, U. Chemical modification of pro-inflammatory proteins by peroxynitrite increases activation of TLR4 and NF-kappaB: Implications for the health effects of air pollution and oxidative stress. Redox Biol. 2020, 37, 101581. [CrossRef]

18. Huang, F.M.; Chang, Y.C.; Lee, S.S.; Yang, M.L.; Kuan, Y.H. Expression of pro-inflammatory cytokines and mediators induced by Bisphenol A via ERK-NFkappaB and JAK1/2-STAT3 pathways in macrophages. Environ. Toxicol. 2019, 34, 486-494. [CrossRef]

19. Ni, Y.L.; Shen, H.T.; Lee, M.W.; Yeh, K.L.; Chiang, C.Y.; Kuan, Y.H. Safrole-induced expression of proinflammatory responses is associated with phosphorylation of mitogen-activated protein kinase family and the nuclear factor-kappaB/inhibitor of kappaB pathway in macrophages. Tzu Chi Med. J. 2020, 32, 344-350.

20. Kuan, Y.H.; Huang, F.M.; Li, Y.C.; Chang, Y.C. Proinflammatory activation of macrophages by bisphenol A-glycidyl-methacrylate involved NFkappaB activation via PI3K/Akt pathway. Food Chem. Toxicol. 2012, 50, 4003-4009. [CrossRef]

21. Wan, Q.; Yang, M.; Liu, Z.; Wu, J. Atmospheric fine particulate matter exposure exacerbates atherosclerosis in apolipoprotein E knockout mice by inhibiting autophagy in macrophages via the PI3K/Akt/mTOR signaling pathway. Ecotoxicol. Environ. Saf. 2021, 208, 111440. [CrossRef] [PubMed]

22. Tsai, P.K.; Wu, S.W.; Chiang, C.Y.; Lee, M.W.; Chen, H.Y.; Chen, W.Y.; Chen, C.J.; Yang, S.F.; Yeh, C.B.; Kuan, Y.H. Evaluation of cytotoxicity, apoptosis, and genotoxicity induced by indium chloride in macrophages through mitochondrial dysfunction and reactive oxygen species generation. Ecotoxicol. Environ. Saf. 2020, 193, 110348. [CrossRef] [PubMed]

23. Lin, F.C.; Lee, S.S.; Li, Y.C.; Ho, Y.C.; Chen, W.Y.; Chen, C.J.; Lee, M.W.; Yeh, K.L.; Tsai, S.C.; Kuan, Y.H. Protective Effects of Kirenol against Lipopolysaccharide-Induced Acute Lung Injury through the Modulation of the Proinflammatory NFkB Pathway and the AMPK2-/Nrf2-Mediated HO-1/AOE Pathway. Antioxidants 2021, 10, 204. [CrossRef] [PubMed]

24. Albinet, A.; Leoz-Garziandia, E.; Budzinski, H.; Viilenave, E. Simultaneous analysis of oxygenated and nitrated polycyclic aromatic hydrocarbons on standard reference material 1649a (urban dust) and on natural ambient air samples by gas chromatography-mass spectrometry with negative ion chemical ionisation. J. Chromatogr. A 2006, 1121, 106-113. [CrossRef] [PubMed]

25. IARC Working Group on the Evaluation of Carcinogenic Risks to Humans. Diesel and Gasoline Engine Exhausts and Some Nitroarenes; IARC Monographs on the Evaluation of Carcinogenic Risks to Humans, No. 105; International Agency for Research on Cancer: Lyon, France, 2014. Available online: https:/ / www.ncbi.nlm.nih.gov/books/NBK294270/ (accessed on 13 October 2021).

26. Jayawardena, T.U.; Sanjeewa, K.K.A.; Lee, H.G.; Nagahawatta, D.P.; Yang, H.W.; Kang, M.C.; Jeon, Y.J. Particulate Matter-Induced Inflammation/Oxidative Stress in Macrophages: Fucosterol from Padina boryana as a Potent Protector, Activated via NFKB /MAPK Pathways and Nrf2/HO-1 Involvement. Mar. Drugs 2020, 18, 628. [CrossRef]

27. Hirayama, D.; Iida, T.; Nakase, H. The Phagocytic Function of Macrophage-Enforcing Innate Immunity and Tissue Homeostasis. Int. J. Mol. Sci. 2017, 19, 92. [CrossRef]

28. Xing, Z.; Afkhami, S.; Bavananthasivam, J.; Fritz, D.K.; D’Agostino, M.R.; Vaseghi-Shanjani, M.; Yao, Y.; Jeyanathan, M. Innate immune memory of tissue-resident macrophages and trained innate immunity: Re-vamping vaccine concept and strategies. $J$. Leukoc. Biol. 2020, 108, 825-834. [CrossRef] 
29. Yang, L.; Xie, X.; Tu, Z.; Fu, J.; Xu, D.; Zhou, Y. The signal pathways and treatment of cytokine storm in COVID-19. Signal Transduct. Target. Ther. 2021, 6, 255. [CrossRef]

30. Poznyak, A.V.; Bharadwaj, D.; Prasad, G.; Grechko, A.V.; Sazonova, M.A.; Orekhov, A.N. Anti-Inflammatory Therapy for Atherosclerosis: Focusing on Cytokines. Int. J. Mol. Sci. 2021, 22, 7061. [CrossRef]

31. Boutilier, A.J.; Elsawa, S.F. Macrophage Polarization States in the Tumor Microenvironment. Int. J. Mol. Sci. 2021, 22, 6995. [CrossRef]

32. Hu, B.; Tong, B.; Xiang, Y.; Li, S.R.; Tan, Z.X.; Xiang, H.X.; Fu, L.; Wang, H.; Zhao, H.; Xu, D.X. Acute 1-NP exposure induces inflammatory responses through activating various inflammatory signaling pathways in mouse lungs and human A549 cells. Ecotoxicol. Environ. Saf. 2020, 189, 109977. [CrossRef] [PubMed]

33. Park, E.J.; Park, K. Induction of pro-inflammatory signals by 1-nitropyrene in cultured BEAS-2B cells. Toxicol. Lett. 2009, 184, 126-133. [CrossRef] [PubMed]

34. Huang, C.H.; Wang, S.C.; Chen, I.C.; Chen, Y.T.; Liu, P.L.; Fang, S.H.; Huang, S.P.; Yeh, H.C.; Liu, C.C.; Lee, P.Y.; et al. Protective Effect of Piplartine against LPS-Induced Sepsis through Attenuating the MAPKs/NF- $\mathrm{kB}$ Signaling Pathway and NLRP3 Inflammasome Activation. Pharmaceuticals 2021, 14, 588. [CrossRef]

35. Liu, T.; Zhang, L.; Joo, D.; Sun, S.C. NF-kB signaling in inflammation. Signal Transduct. Target. Ther. 2017, 2, 17023. [CrossRef] [PubMed]

36. Linton, M.F.; Moslehi, J.J.; Babaev, V.R. Akt Signaling in Macrophage Polarization, Survival, and Atherosclerosis. Int. J. Mol. Sci. 2019, 20, 2703. [CrossRef] [PubMed] 